\title{
O INTÉRPRETE DE LÍNGUA BRASILEIRA DE SINAIS/ LÍNGUA PORTUGUESA COMO INTELECTUAL ESPECÍFICO INFAME
}

\author{
THE INTERPRETER OF BRAZILIAN SIGN LANGUAGE/PORTUGUESE AS A \\ SPECIFIC INFAMOUS INTELLECTUAL
}

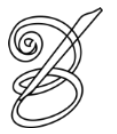 \\ Lucyenne Matos da Costa VIEIRA-MACHADO \\ Universidade Federal do Espírito Santo \\ Joaquim Cesar Cunha dos SANTOS ${ }^{\text {ii }}$ \\ Universidade Federal do Espírito Santo
}

\begin{abstract}
Resumo: Este artigo tem como objetivo discutir a temática dos intérpretes de Libras/LP, bem como a sua atuação, que ganha força em nosso tempo, e justamente por este fato emergem saberes teóricos sobre esses profissionais. Metodologicamente, utiliza-se a pesquisa narrativa, que busca discutir os processos de subjetivação desses sujeitos a fim de criar ferramentas para que uma reflexão possa ser feita quanto à sua atuação, usando como base, na esteira de Foucault, as noções de intelectual específico e infame. Assim, as narrativas exemplificam mecanismos pelos quais se produz experiências e atitudes infames. Como resultado, foi possível perceber que cada sujeito, em determinado momento de sua história/vida, foi/é um intelectual específico quando problematiza sua própria função, a fim de produzir outras atitudes na prática do trabalho de interpretação na educação de surdos.
\end{abstract}

Palavras-chave: Intérpretes de Libras/LP. Surdos. Intelectual específico. Infame.

Abstract: This paper is part of a concluded Master's degree research. The discussion applied on this work is about Brazilian Sign Language (Libras)/Portuguese interpreters, professionals who have become necessary for the inclusion of the deaf person. Their work, therefore, becomes important in a way that theoretical knowledge emerges over these professionals. Methodologically, the narrative research is used in order to understand these individuals' subjetivation processes and to create tools to ponder on their performance using as a theoretical basis, based on Foucault, the notions of specific intellectual and infamous. The narratives are analyzed as mechanisms by which experiences and infamous attitudes are produced. As a result, it was possible to realize that each person in determined moment of his/her history/life was/is a specific intellectual when problematizes his/her own function, in order to produce other attitudes in the praxis of interpretation work on deaf people's education. Key words: Libras/Portuguese interpreter. Deaf people. Specific intellectual. Infamous.

RECEBIDO EM: 20 de março de 2018

ACEITO EM: 30 de novembro de 2018

PUBLICADO EM: janeiro 2019

MACHADO, SANTOS. O intérprete de Língua Brasileira de Sinais/ Língua Portuguesa como intelectual específico infame

Belas Infiéis, v. 8, n. 1, p. 93-104, 2019. DOI: 10.26512/belasinfieis.v8.n1.2019.13085 


\section{Introdução: iniciando a conversa}

om a inclusão social dos sujeitos surdos, o intérprete de Língua Brasileira de Sinais (Libras)/Língua Portuguesa (LP) passa a ser fundamental. A demanda por esses profissionais causa um impacto em sua presença nas relações estabelecidas entre surdos e ouvintes em situações de interação social. Diante dos problemas de comunicação enfrentados pelos sujeitos surdos usuários de Libras, surge a necessidade de intérpretes que medeiem sua relação com os ouvintes em diferentes situações sociais. Assim, percebemos a alteração do status dessa profissão no contexto social ao longo da história.

A fim de compreender como os sujeitos que atuam como intérpretes de Libras/LP se constituem, propomos aqui uma reflexão sobre como esses profissionais se subjetivam intérpretes, independentemente de sua formação, a partir dos diferentes rituais possíveis. Nossa hipótese é a de que as subjetividades-intérpretes são produzidas em diferentes espaços-tempos em que diferentes rituais aletúrgicos ${ }^{1}$ as caracterizam como tal.

Este artigo é um recorte de uma pesquisa de mestrado concluída, intitulada "A formação do tradutor-intérprete de Língua Brasileira de Sinais como intelectual específico: o trabalho de

94 interpretação como prática de cuidado de si”. Tem como objetivo central compreender como o sujeito intérprete de Libras/LP se constitui como tal e se reconfigura, seja egresso de famílias de surdos ou não, de instituições religiosas ou de outros diferentes espaços. Enfim, como esse sujeito se subjetiva intérprete profissional e se vê no processo de ensino de alunos surdos, problematizando as questões emergentes e/ou cotidianas na área? E como se constitui como sujeito de atitude diante de tais questões, com práticas que vão além das próprias normativas da função? Como tal atitude implica certa maneira de estar atento às práticas e ao que se passa no pensamento? Perguntas como essas nos mobilizam frente às diferentes situações vividas por este profissional em nosso tempo.

A metodologia empregada na construção dos dados parte das narrativas obtidas por meio de entrevistas feitas individualmente com 11 intérpretes de Libras/LP em diferentes processos de formação e diferentes momentos em que atuam com a prática da interpretação. A pergunta inicial para a produção das narrativas foi: em sua trajetória na vida pessoal e profissional, como suas escolhas contribuíram para o que você é hoje?

Com essa pergunta, a intenção não foi buscar respostas "certas", nem distinguir o certo e o errado, nem o verdadeiro e o falso, mas buscar as verdades, os rituais e as aleturgias que subjetivam esses intérpretes de Libras/LP e entender como são subjetivados pelo próprio regime 
de verdades construído em sua prática profissional. Na discussão dos dados, a partir de uma teorização foucaultiana, utilizaremos as noções de intelectual específico e infame.

Este texto é composto por duas partes, além da introdução e das considerações finais, nas quais discutiremos os percursos teórico-metodológicos da pesquisa a partir da produção dos dados, operando com as ferramentas conceituais acima descritas.

\section{Caminhos teórico-metodológicos}

O percurso metodológico deste trabalho tem como inspiração a aula de 5 de janeiro de 1983, de Foucault, no curso O governo de si e dos outros (FOUCAULT, 2010). Na referida aula, Foucault traz a "história do pensamento"2 e explica como dois métodos, um que chama de "história das mentalidades" e outro de "história das representações", estão inseridos na "história do pensamento" (FOUCAULT, 2010).

Por "história das mentalidades", entende-se que os sujeitos, ao narrarem-se, fazem uma análise dos comportamentos efetivos e expressões que podem acompanhar esses comportamentos, por traduzi-los ou até mesmo justificá-los. Por "história das representações", entende-se a análise do papel que desempenham as representações, ou seja, uma análise das ideologias e uma análise dos valores representativos, considerando o que é posto como regra, com um status de verdade, uma referência, uma análise das representações geradas por esse

conhecimento. É nesse contexto que nos voltamos para as práticas dos intérpretes de Libras/LP, a partir das narrativas desses profissionais, a partir das suas “confissões". Confissão, aqui neste texto, não diz respeito ao ritual de busca pela indulgência dos deuses ou juízes, mas à operação de uma subjetivação (FOUCAULT, 2010).

A partir das narrativas obtidas por meio das confissões desses sujeitos, podemos seguir as pistas de que suas práticas, suas atitudes, os constituem, em algum momento, como intelectuais específicos. Foram entrevistados 11 intérpretes de Libras/LP em diversos níveis de formação. São intérpretes que atuam em diferentes espaços sociais onde os sujeitos surdos estão inseridos.

Em A casa dos loucos, Foucault (2013a, p.193) pergunta "se pode haver melhor prova, indício mais seguro do que a confissão do próprio sujeito [...]?”. Para Foucault, a confissão é uma das técnicas de si, um dos modos pelos quais o indivíduo pode estabelecer uma relação consigo mesmo e produzir uma série de operações sobre seu corpo, seus pensamentos e sua conduta. 
A escolha desse procedimento teórico-metodológico se dá por uma modalidade discursiva da experiência de si, da autoidentidade, que incita o sujeito a observar-se, dizer-se, julgar-se, mostrar sua identidade. Segundo Larrosa (1994),

[a] confissão, tal como o exame em Vigiar e Punir, é um dispositivo que integra a produção do saber e a cerimônia do poder, o lugar onde a verdade e o poder confluem. O sujeito confessante é atado à lei e se reconhece a si mesmo em relação à lei. A confissão é um dispositivo que transforma os indivíduos em sujeitos nos dois sentidos do termo: sujeitos à lei e sujeitados à sua própria identidade. [...]. Aprender a ver-se, a dizer-se, ou a julgar-se é aprender a fabricar o próprio duplo. E a "sujeitar-se" a ele. Esse duplo está construído pela composição do eu que vejo quando me observo a mim mesmo, do eu que expresso quando me digo a mim mesmo, do eu que narro quando construo temporalmente minha própria identidade, do eu que julgo quando me aplico um critério, do eu que domino quando me governo (LARROSA, 1994, p. 79-80).

No contexto da formação do profissional intérprete de Libras/LP, pela política vigente de inclusão e acessibilidade, coloca-se a questão sobre quem é esse sujeito que, envolvendo-se de alguma maneira com práticas que não se limitam ao ato tradutório, pode reformular sua própria relação com o saber, reconhecendo que este é intrínseco aos dispositivos de poder, que precisa trabalhar a partir de sua própria situação. A partir das narrativas, buscamos entender os processos de formação e subjetivação dos intérpretes.

Segundo Foucault (2014a, p.11), “[...] o homem se dá seu ser próprio a pensar [...] quando reflete sobre si como ser vivo, ser falante e ser trabalhador, quando ele se julga [...]". A experiência reflexiva é concreta, histórica e culturalmente situada. Para Foucault, há um uso particular da história:

Uma história que não seria aquela do que poderia haver de verdadeiro nos conhecimentos; mas uma análise dos 'jogos de verdade', dos jogos entre o verdadeiro e o falso, através dos quais o ser se constitui historicamente como experiência, isto é, como podendo e devendo ser pensado (FOUCAULT, 2014a, p. 11).

Ao pensarmos a formação, neste texto, a articulamos tanto a um conjunto de conhecimentos específicos que são ministrados ou adquiridos, quanto ao uso da perspectiva do cuidado de si, da estética da existência das técnicas de si. O cuidado de si diz respeito à maneira pela qual cada indivíduo constitui a si mesmo como sujeito de sua própria conduta.

[...] é o que se poderia chamar de "artes da existência". Estas devem ser entendidas como práticas racionais e voluntárias pelas quais os homens não apenas determinam para si mesmos regras de conduta, como também buscam transformar-se, modificarse em seu ser singular, e fazer de sua vida uma obra que seja portadora de certos

MACHADO, SANTOS. O intérprete de Língua Brasileira de Sinais/ Língua Portuguesa como intelectual específico infame

Belas Infiéis, v. 8, n. 1, p. 93-104, 2019. DOI: 10.26512/belasinfieis.v8.n1.2019.13085 
valores estéticos e que corresponda a certos critérios de estilo (FOUCAULT, 2014b, p.193).

Exercitar o pensamento nessa direção é acreditar que esse sujeito intérprete, por possuir certo número de conhecimentos e agir teoricamente sobre problemas bem definidos, tem, segundo Foucault (2013b), o papel de um intelectual e, a partir da reflexão sobre a relação do seu próprio trabalho com a vida, é capaz de problematizar para reformular as perguntas.

Para Foucault (2013b), o trabalho do intelectual não é modelar a vontade dos outros, mas interrogar aquilo que está posto como uma verdade e parece evidente, abalar costumes. Ele propõe um intelectual que renuncie a considerar-se a consciência de toda a sociedade, o portador da verdade, e que se permita discernir qual será o impacto de sua atitude e que tipo de relação se estabelecerá entre seu trabalho teórico e sua prática de vida - um intelectual diferente do que é universal, um intelectual específico (GROS, 2004, p. 44). Assim, por meio de uma inspiração foucaultiana junto a outros autores que dialogam nessa direção, utilizamos a noção de intelectual específico para pensar a função do profissional intérprete de Libras/LP no contexto atual.

É necessário pensar o papel do intérprete como intelectual em nossa contemporaneidade; afinal, sua atuação no atual momento da história pode ter diferentes configurações. É ao cuidar de si, atento ao que pensa e ao que se passa no pensamento, que esse profissional, como intelectual, pode falar sobre uma prática educativa inclusiva, trazendo uma discussão produtiva sobre sua atuação na educação de surdos.

Ao utilizar-se a noção de intelectual específico para pensar a função do profissional intérprete de Libras/LP no contexto atual, compreende-se que, em determinado momento de sua história, o intérprete assume para si essa responsabilidade de não prescrever, definindo o que é e o que não é, ou será; antes, há a responsabilidade de reformular os problemas, que muitas vezes vão além de um envolvimento e comprometimento com a profissão e com a atividade de interpretação. Segundo Foucault (2013b), "a função dele não é modelar a vontade dos outros, mas renunciar se considerar portador da verdade" (FOUCAULT, 2013b, p.48).

\section{O intérprete de libras/língua portuguesa como intelectual específico infame}

Abordar a noção de inclusão neste trabalho implica discutir os mecanismos utilizados para que os sujeitos, público-alvo da educação especial, tenham garantido o ensino. Segundo Veiga-Neto (2007, p. 949), "as políticas de inclusão escolar funcionam como um poderoso e 
efetivo dispositivo biopolítico ${ }^{3}$ a serviço da segurança das populações”. Em termos simples, a inclusão tem como propósito a diminuição do risco social quanto à população que se deseja incluir.

A respeito disso, pode-se afirmar que os intérpretes também estão subjetivados por decisões regulamentares, leis, medidas administrativas e discursos (FOUCAULT, 2013b). Por meio de instituições, são direcionados, bloqueados, estabilizados, conduzidos, tendo acesso às regras impostas para conhecerem e obedecerem. Os intérpretes de Libras/LP que conduzem são também conduzidos a assemelhar-se a um modelo de intérprete de Libras/LP, sendo tais valores discutidos e postulados. Assim, tornam-se agentes biopolíticos na inclusão dos sujeitos surdos.

O intérprete de Libras/LP como intelectual específico traz para o processo de inclusão dos surdos e para outras esferas possibilidades que estão além do ato de traduzir e interpretar de uma língua para outra, além dos códigos de ética, bem como os rituais de legitimação de intérpretes de Libras/LP. O intérprete, como intelectual específico, está de acordo com o que pensa, e o que faz está em harmonia com o que vive.

O intérprete de Libras/LP que é conhecedor das práticas que definem a educação de surdos na perspectiva da inclusão vai interrogar tais práticas, problematizá-las, pensar, assumir uma postura diante do governo dos outros. Com uma atitude, vai resistir à opinião do senso comum, viver o que pensa como verdade.

Ainda na esteira de Foucault, a noção de "infame", bem como a noção de intelectual específico, estão na ordem da heterotopia. A perspectiva do "infame" é romper

[...] com os tipos de ligações estabelecidas entre o poder, a verdade, o discurso e o cotidiano à medida que leva em consideração todo o tipo de relação que está em jogo na constituição de subjetividades. Ele pulveriza e espraia as dimensões de possibilidades de experiências de rompimento com o localizado, o hegemônico, o homônimo (CARVALHO, 2014, p.104).

O infame é alguém destituído de fama, nem sempre observado, dignificado ou invocado como participante da história, mas que faz que existam as experiências menores, muitas vezes desvalorizadas, mas que por estarem ali fazem emergir outra forma de ver o presente. O infame passará além dos rituais que o legitimam e buscará em suas experiências, sejam elas singulares ou não, aquilo que "rompe com os tipos de ligações estabelecidas [...] com o localizado, o hegemônico, o homônimo" (CARVALHO, 2014, p.104).

Foucault (2006a), em seu texto “A vida dos homens infames", se interessa em pensar sobre vidas que, de uma certa forma, eram condenadas por comportamentos específicos que 
destoavam daquilo que estava na ordem. Segundo o autor, o interesse por essas vidas se dá a partir da leitura de duas notícias.

Jean Antoine Touard, posto no Chateau de Bicêtre, no dia 21 de abril de 1701: Recoleto apóstata, sedicioso capaz dos maiores crimes, sodomista, ateu, se é que se pode sê-lo; um verdadeiro monstro de abominação que seria menos inconveniente sufocar do que deixar livre (FOUCAULT, 2006, p. 204).

Foucault confessa que se sente abalado e de certa forma emocionado com o estilo clássico, adornado de frases sobre esses personagens (citamos aqui apenas uma dessas notícias como exemplo). Frases que eram recheadas de excessos, sobre essas vidas miseráveis. E então parte para uma reflexão, não se importando com a existência ou não desses personagens, se eram de fato obscuras e desventuradas. $\mathrm{O}$ autor continua mostrando o desejo de que esses sujeitos fossem reais e que se pudesse dar nomes, um lugar, uma data, por trás desses adjetivos, na maioria das vezes exagerados, falsos, mentirosos e até mesmo injustos.

Foucault (2006) também deseja que, se existissem esses personagens, suas vidas fossem mesmo obscuras e nada convencionais. "[...] que não fossem dotadas de nenhuma dessas grandezas estabelecidas e reconhecidas - as do nascimento, da fortuna, da santidade, do heroísmo, ou do gênio. Que pertencessem a essas milhares de existências destinadas a passar sem deixar rastro". (FOUCAULT, 2006, p. 207).

E assim, surge a pergunta

[...] por que não ir escutá-las lá onde, por elas próprias, elas falam? [...] o ponto mais intenso de suas vidas, aquele que concentra sua energia, é bem ali onde se chocam com o poder, se debatem com ele, tentam utilizar suas forças ou escapar de suas armadilhas. (FOUCAULT, 2006, p. 208).

E assim, pensando sobre as vidas infames com o autor, adjetivarmos o intérprete como infame neste mundo é de, alguma forma, compreender que são vidas invisibilizadas e tratadas como se não tivessem existido. Vidas que só sobrevivem do embate com um poder que previa apagá-las, aniquilar e moldar sua forma de existir.

Não obstante, um modo de vida infame pode ser a possibilidade de, sobre esse poder, ao menos por um instante, “[...] dele se apropriar, canalizá-lo, captá-lo e incliná-lo na direção do que se quer; é preciso, para usá-lo em seu benefício, seduzi-lo [...]” (FOUCAULT, 2006, p. 215). 
Assim, quando a atitude infame de vida do intérprete em movimento ecoa como intelectual específico, causa uma ruptura, segundo Carvalho (2014, p. 104), “com o que está estabelecido no âmbito do poder, da verdade, do discurso e do cotidiano, levando em conta o que está em jogo na constituição de subjetividades". Nessa sua reflexão consigo mesmo, ele se observa, se decifra, se interpreta, se julga, se narra ou se domina. Essa ação de aprender ou de modificar-se não é o resultado da influência de outros, mas das relações que o sujeito estabelece consigo mesmo (LARROSA, 1994).

Por meio da reflexão sobre si, a atitude infame, assumida pelo intérprete, pode produzir uma existência ética e estética, ao operar em suas práticas, a partir de certos rituais aletúrgicos, um certo modo de olhar-se, expressar-se, narrar-se, dominar-se e julgar-se, que, segundo Larrosa (1994) constituem-se como tecnologias do eu.

Destarte, no uso dessas tecnologias na produção de suas subjetividades, novas verdades vão constituindo esse eu-intérprete a partir da experiência vivida na relação com esse poder político que o institui, o submete, e o nomeia. A atitude infame, produzida por esses rituais, possibilita formas de se relacionar com esse poder a partir da captura, sedução e uso de outras 100 formas dentro dos espaços institucionalizados.

E por isso, ao lançarmos mão da noção de intelectual específico, o eu-intérprete de Libras/LP infame não é depositário de certo saber, mas fala a partir de um saber local, que trabalha a partir de sua própria situação. Como sujeito infame, rompe com o que está estabelecido, apresentando o que é fora do comum ou que, por não estar na norma, é perigoso.

[...] a primeira coisa que eu vou fazer, eu não sei se vão me apoiar, mas eu, como intérprete, eu não sei ficar olhando para a cara do menino e ele olhando para mim e fazendo nada. Então, eu tive as minhas ações. (INTÉRPRETE R) ${ }^{4}$

Os intérpretes de Libras/LP, em sua prática intelectual, não reivindicam a universalidade do que é justo, correto e verdadeiro; antes, problematizam, pondo em jogo seu ofício. Como intelectual específico, é sujeito de produção da verdade, participando na formação de uma vontade política, desempenhando seu papel de cidadão.

O sujeito intérprete de Libras/LP, como intelectual específico infame, evidencia sua verdade e colabora para a existência de possibilidades na área da educação dos surdos, buscando, por sua atitude política, mudanças nas direções até então estabelecidas por meio de discursos como sendo a verdade a que todos precisam submeter-se. 
Nesse respeito, sua atuação no atual momento da história pode ter outras configurações. Quando fizeram suas “confissões” e falaram de inclusão, alguns disseram o seguinte:

\begin{abstract}
Então, as estratégias que hoje eu estou utilizando na sala de aula estão sendo diferentes. Eu não fico sentada, eu fico em pé [...]. O professor, no início, vê como uma coisa diferente, mas ele vai junto. Eu fiquei com outra disciplina, desenho técnico, eu fiquei em pé do lado do quadro, ele desenhando o triângulo e eu do lado dele. Aí, ele falou assim: "Eu tenho uma assistente nova aqui agora". Eu falei: "Tudo certinho agora para o senhor, professor?". "Tudo tranquilo, eu estou achando até tudo bom, porque a [aluna] está me olhando". Então, aí, o contato do professor com a surda. Eu me senti muito mais à vontade [...]. Nas duas primeiras aulas, eu fiz de acordo como o [outro] intérprete fazia. Sentei no cantinho, é como se tivesse duas salas, uma sala dos ouvintes e uma sala sozinha, eu e a surda. Eu me incomodava com isso. (INTÉRPRETE "S") $)^{5}$
\end{abstract}

Subjetivados por discursos construídos, os objetos, os gestos corporais e a linguagem passam por um processo de transformação, adquirindo um significado denso. Assim, muitas vezes, sem um processo forte de discussão e reflexão, verdades são constituídas a partir de comportamentos repetidos constantemente. Usar roupa de cor única e não usar pulseira ou relógio são práticas entre os tradutores-intérpretes de Libras/LP. Desse modo, as verdades que são construídas por meio de práticas rotineiras ficam no estágio do hábito, sem "reinterrogar as evidências e os postulados, sem abalar os costumes, os modos de se fazer e de pensar" (GROS, 2004, p.45).

Enfim, não é objetivo deste texto determinar o certo e o errado, nem dar receitas para os profissionais na área de tradução e interpretação na língua brasileira de sinais e nas suas relações com surdos. Não há um momento, uma situação igual, idêntica. Cada profissional tem que usar os mecanismos que medeiam a experiência de si.

\title{
Considerações finais - ressonâncias
}

$\mathrm{Na}$ introdução deste trabalho, apresentamos o cenário, o sujeito surdo em situações de interação social demandando a presença do profissional intérprete de Libras/LP com o objetivo de inclusão e o impacto da presença desse profissional mediando o processo de interação: surdo e sociedade. Abordamos ainda o efeito desse impacto na subjetivação desses sujeitos como profissionais.

Também expusemos os percursos metodológicos a partir das narrativas e das "confissões" e como esses procedimentos contribuíram para a produção de discursos; pudemos discutir, ainda, as práticas discursivas de subjetivação desses sujeitos. 
Para entender os processos de subjetivação dos intérpretes de Libras/LP, buscamos na caixa de ferramentas teórico-metodológicas as noções de intelectual específico e infame, cunhadas por Foucault, com o objetivo de responder à questão inicial deste trabalho. Segundo Foucault (2013b), a figura de um intelectual universal (aquele que reivindica a universalidade do que é justo, correto e verdadeiro) diverge da figura do intelectual específico (aquele que problematiza por retomar a medida das regras e das instituições, pondo em jogo esse ofício).

Já o infame é alguém destituído de fama e buscará ir além da valorização inflexível dos rituais institucionais que o legitimam. Buscará em suas experiências, sejam estas singulares ou não, aquilo que "rompe com os tipos de ligações estabelecidas [...] com o localizado, o hegemônico, o homônimo" (CARVALHO, 2014, p. 104).

Os mecanismos ótico, discursivo, moral de transformação e de condução contribuíram para entender como se veem, narram, julgam, se transformam e se conduzem. Ao trazer-se o assunto sobre os intérpretes de Libras/LP neste trabalho, busca-se olhar possibilidades sobre tais indivíduos na área da educação. Todos que estão nesse jogo são levados a refletir sobre as práticas de subjetivação e, com isso, entender a possibilidade de sujeitos de ação na direção de 102 suas consciências.

A atuação do intérprete de Libras/LP em todo esse processo e nas suas relações com os sujeitos surdos deve cuidar para não exercer uma dominação, como a de uma classe sobre outra, mas criar experiências nos atravessamentos que constituirão os sujeitos. O controle e a condução dos sujeitos não são concretizados apenas por um poder oriundo do Estado, mas contam com uma série de organizações, instituições, procedimentos e agentes que exercem tal poder na sociedade.

Assim, foi possível perceber que cada sujeito, em determinado momento de sua história/vida, foi/é e pode ser um intelectual específico quando busca problematizar o que lhe é posto. A atitude no cuidado de si, com uma ética não engessada, mostra possibilidades no que se refere à educação de sujeitos surdos.

Ao concluir, enfatizamos que não negamos a ordem discursiva da inclusão nem a ela nos contrapomos; não rejeitamos o que está sendo feito, tampouco os profissionais envolvidos. Buscamos entender os porquês, os efeitos das práticas e ações que ordenam esse processo, que são necessárias, e como os profissionais envolvidos podem, no presente, trazer outro olhar para o que está posto como verdades salvacionistas que resolverão as questões na educação dos surdos. 


\section{REFERÊNCIAS BIBLIOGRÁFICAS}

CARVALHO, Alexandre F. de. Foucault e a função-educador. 2a . ed. Ijuí, RS: Editora Unijuí, 2014.

FOUCAULT, Michel. A vida dos homens infames. In: Michael Foucault. Estratégia, podersaber. Ditos e escritos IV. Rio de Janeiro: Forense Universitária, 2006a. (p.203-222).

FOUCAULT, Michel. Os intelectuais e o poder. In: Michael Foucault Estratégia, podersaber. Col. Ditos e Escritos IV. 2.ed. Rio de Janeiro: Forense Universitária, 2006b.

FOUCAULT, Michel. O governo de si e dos outros: curso no Collège de France (19821983). Tradução Eduardo Brandão. São Paulo: Editora WMF Martins Fontes, 2010.

FOUCAULT, Michel. Do governo dos vivos: Curso no Collège de France, 1979-1980: excertos / Michel Foucault; organização de Nildo Avelino. - São Paulo: Centro de Cultura Social; Rio de Janeiro: Achiamé, 2a . ed. revista e ampliada, 2011.

FOUCAULT, Michel. A casa dos loucos. In: Michael Foucault. Microfísica do poder. $27^{a}$ edição. São Paulo: Graal, 2013a.

FOUCAULT, Michel. Os intelectuais e o poder. In: Michael Foucault. Microfísica do poder. $27^{\mathrm{a}}$ edição. São Paulo: Graal, 2013 b.

FOUCAULT, Michel. O uso dos prazeres e as técnicas de si. In: Michael Foucault. Ética, sexualidade, política. Traduzido por: Elisa Monteiro e Inês Autran Dourado Barbosa. Col. Ditos e Escritos V. 3.ed. Rio de Janeiro: Forense Universitária, 2014a.

FOUCAULT, Michel. A Ética do cuidado de si como prática da liberdade. In: Michael Foucault. Ética, sexualidade, política. Tradução de Elisa Monteiro e Inês Autran Dourado Barbosa. Col. Ditos e Escritos V. 3.ed. Rio de Janeiro: Forense Universitária, 2014b.

GROS, Frédéric; ARTIÈRES, Philippe et al. Foucault: a coragem da verdade. Tradução de Marcos Marcionilo, São Paulo: Parábola Editorial, 2004.

LARROSA, Jorge. “Tecnologias do eu e educação”. IN: Tomaz Tadeu Silva. O sujeito da educação. Petrópolis: Vozes, p.35-86, 1994.

VEIGA-NETO, A.; LOPES, M. C. Inclusão e governamentalidade. Educ. Soc. Campinas, vol. 28, n. 100 - Especial, p. 947-963, out. 2007.

\footnotetext{
i Lucyenne Matos da Costa VIEIRA-MACHADO - Doutora (2012) e Mestre (2007) em Educação pela Universidade Federal do Espírito Santo. Graduada em Pedagogia (2003) pela mesma instituição. Realizou estágio pós-doutoral no Programa de Pós-Graduação em Educação da Universidade do Vale do Rio dos Sinos. É professora adjunta III na Universidade Federal do Espírito Santo. Vitória, ES, Brasil.

Lattes: http://lattes.cnpq.br/6809535589391676 E-mail: lumatosvieiramachado@gmail.com

ii Joaquim Cesar Cunha dos SANTOS - Mestre em Educação (2016) pela Universidade Federal do Espírito Santo. Especialista em Educação Especial na Perspectiva da Inclusão (2014) pela mesma instituição. Graduado em
} 
Letras/Libras (2012) pela Universidade Federal de Santa Catarina. Tradutor e Intérprete de Libras na Universidade Federal do Espírito Santo. Vitória, ES, Brasil.

Lattes: http://lattes.cnpq.br/6090932065520849 E-mail: Cesar.cunha.ils@gmail.com

${ }^{1}$ Segundo Foucault $(2011$, p.8): “[...] poderíamos chamar de 'aleturgia’ o conjunto dos procedimentos possíveis, verbais ou não, pelos quais se revela o que é dado como verdadeiro em oposição ao falso, ao oculto, ao indizível, ao imprevisível, ao esquecimento, e dizer que não há exercício do poder sem algo como a aleturgia”.

${ }^{2}$ E por "pensamento", Foucault queria dizer uma análise do que se poderia chamar de focos de experiência, "os quais se articulam uns sobre os outros: primeiro, as formas de um saber possível; segundo, as matrizes normativas de comportamento para os indivíduos e, enfim, os modos de existência virtuais para sujeitos possíveis. [...] é a articulação dessas três coisas que podemos chamar, creio, de "foco de experiência" (FOUCAULT, 2010, p.4).

${ }^{3}$ A biopolítica tem por finalidade gerenciar a saúde, higiene, alimentação, sexualidade, natalidade, etc., na medida em que tais gestões se tornam apostas políticas.

${ }^{4}$ SANTOS, Joaquim Cesar Cunha dos. A formação do tradutor-intérprete de língua brasileira de sinais como intelectual específico: o trabalho de interpretação como prática de cuidado de si. 97 f. Dissertação (Mestrado em Educação) - Universidade Federal do Espírito Santo, Centro de Educação. - 2016. Entrevista realizada em $10 / 12 / 2015$.

${ }^{5}$ SANTOS, Joaquim Cesar Cunha dos. A formação do tradutor-intérprete de língua brasileira de sinais como intelectual específico: o trabalho de interpretação como prática de cuidado de si. 97 f. Dissertação (Mestrado em Educação) - Universidade Federal do Espírito Santo, Centro de Educação. - 2016. Entrevista realizada em $10 / 12 / 2015$ 